\title{
Epidural Abscess Causing Tetraparesis: Case Report
}

\author{
R. Chappel, M.D., ${ }^{3}$ J. A. Verhelst, M.D., ${ }^{1}$ J. M. Nagler, M.D., ${ }^{1}$ L. Dom, \\ M.D., ${ }^{1}$ B. Appel M.D., ${ }^{2}$ and P. Herregods, M.D. ${ }^{3}$ \\ ${ }^{1}$ Medical Intensive Care Unit-Department of Internal Medicine, ${ }^{2}$ Department \\ of Neuroradiology and ${ }^{3}$ Department of Physical Medicine and Rehabilitation. \\ Middelheimziekenhuis, Lindendrief 1, B-2020 Antwerp, Belgium
}

\section{Summary}

A case is presented of a 26-year-old male with a 8-day history of fever and back pain, and limb weakness beginning 24 hours before admission. An abscess caused by a staphylococcus aureus was localised in the thoracic paravertebral region with penetration in the subarachnoidal space at T1. Myelography appeared to be superior to $C A T$-scan and NMRI of the cervico-thoracal region in supporting the diagnosis. Treatment by laminectomy of C7-T3 48 hours after admission did not lead to neurological improvement and an incomplete tetraplegia persisted. The importance and difficulty of early diagnosis is stressed.

Key words: Spinal epidural abscess; CAT-scan; Nuclear magnetic resonance imaging (NMRI); Myelography.

\section{Introduction}

Spinal epidural abscess is an uncommon condition and a relatively rare cause of non-traumatic para- or tetraplegia. Early symptoms such as fever, back pain and limb weakness are not always distinctive, so that confusion can arise with more common diseases. As shown in the following case other factors such as an unusual presentation may cause a delay in diagnosis. Nevertheless, an early diagnosis is of great importance, as an acquired para- or tetraplegia for over 48 hours stands little chance of improvement (Baker et al., 1975, Ditullio, 1977, Hancock, 1973, Verner et al., 1985).

\section{Case report}

A 26-year-old teacher was admitted on the 17th of June 1985 to hospital. Eight days previously he complained of moderate cervical and thoracic pain which was attributed to a 'flu-like infection. Three days later the pain got worse and 
the temperature rose to $38.5^{\circ} \mathrm{C}$. He was treated with aspirin and the next day pain and temperature disappeared. Two days before admission however the pain returned with radiation to the right arm. The evening before admission he noticed weakness and paresthesiae in both legs, this got worse in the next 24 hours and he developed urinary retention. He was admitted to hospital the next evening.

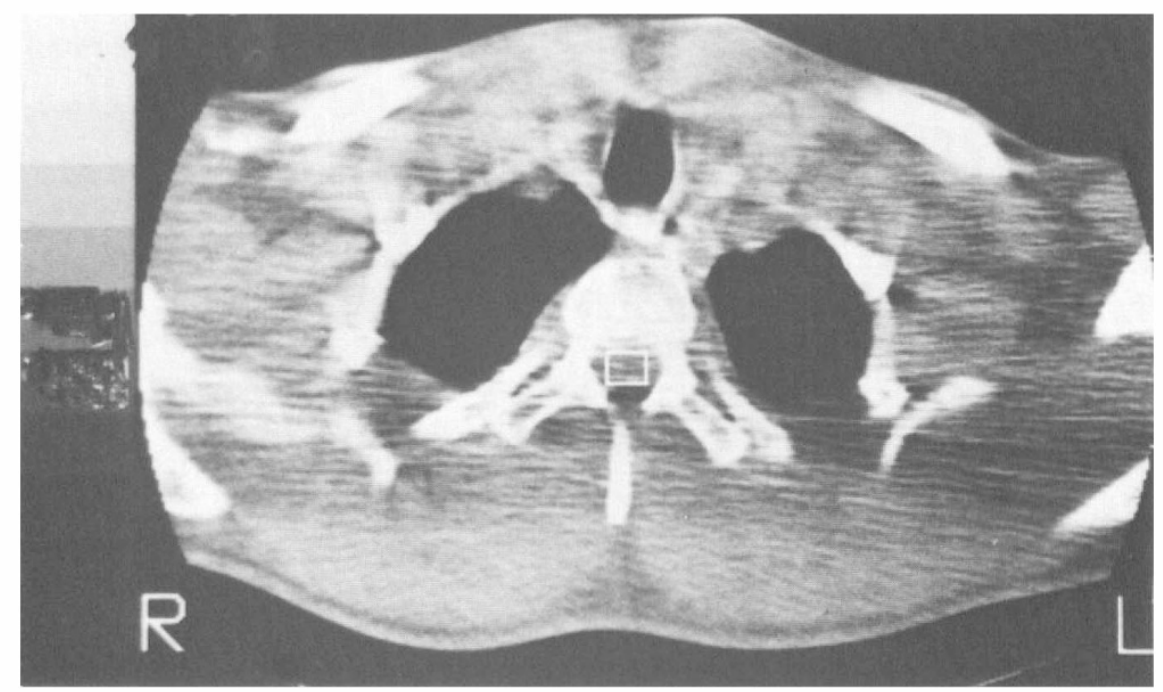

Figure 1. CAT-scan showing only a swelling of the perivertebral area (level T1).

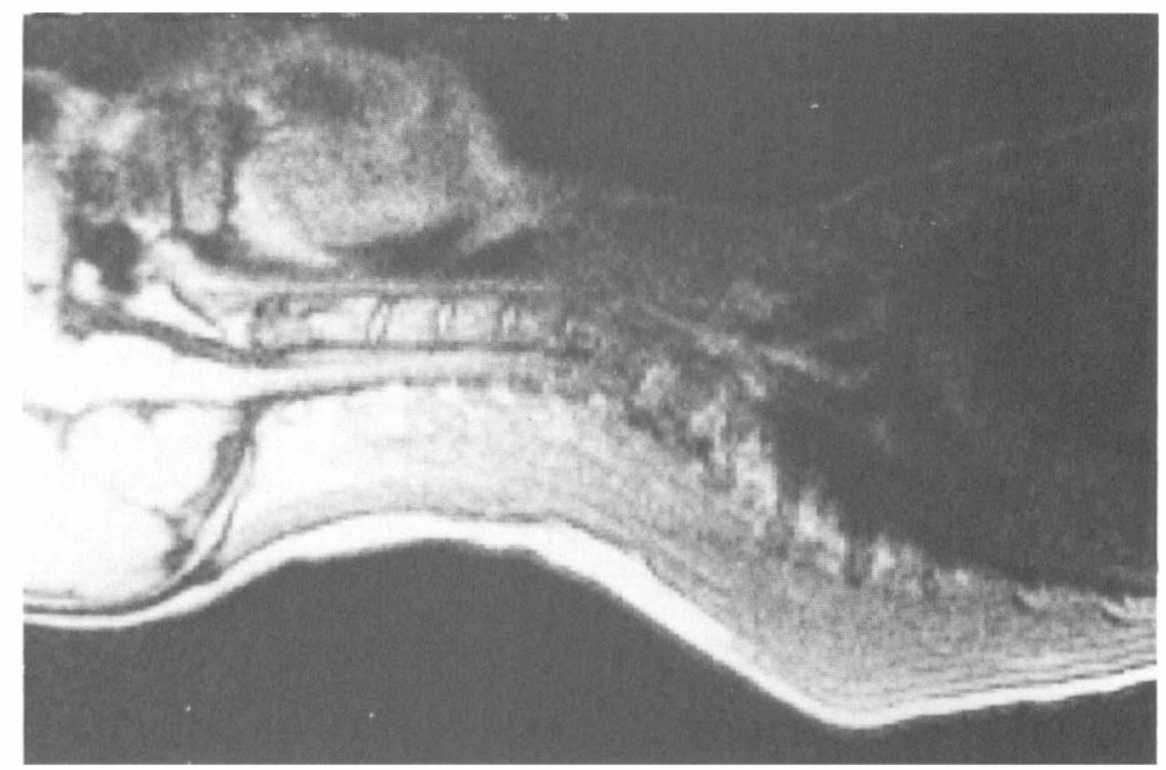

Figure 2. N.M.R.I.: pathological signal in the subarachnoid space of the cervical medulla. 
On admission general physical examination was normal except for a globus vesicalis. The blood pressure was $130 / 90 \mathrm{mmHg}$, pulse rate $76 / \mathrm{min}$, temperature $37 \cdot 6^{\circ} \mathrm{C}$.

Neurological examination showed a nearly complete flaccid paralysis of both legs with absent knee-jerks and diminished ankle-jerks. Plantar responses were normal. There was a sensory level, to all modalities at T2. Reflexes were brisk in the arms, there was slight distal paresis of the right arm. Cranial nerves were normal. There were no signs of meningeal irritation but he had neck pain without localised tenderness. The skin in the dorsal region appeared normal.

A lumbar puncture was performed and revealed a normal pressure, and Queckenstedt's test was normal. The CSF contained 330 white blood cells $/ \mathrm{mm}^{3}$ with $95 \% \mathrm{PN}$ and 3 red blood cells $/ \mathrm{mm}^{3}$. The glucose content was $49 \mathrm{mg} \%$, protein level $660 \mathrm{mg} \%$. Blood cultures and culture of the CSF were sterile.

Electromyography of both legs was normal. X-rays of the cervical and dorsal spine revealed no abnormalities. A bone scan showed no evidence of osteomyelitis.

A CAT-scan from the base of the skull to T4 level showed a swelling in the perivertebral area at $\mathrm{T} 1$ suggestive of an inflammatory lesion (Fig. 1). No abscess could be distinguished and the medulla appeared normal. In the NMRI, taken of the whole spine, the cervical medulla was not well delineated due to a pathological high signal in the subarachnoid spaces (Fig. 2). This signal appeared to stop at the level $\mathrm{C} 0-\mathrm{C} 1$. Positive differentiation between cord enlargement or invasion of the subarachnoidal spaces was impossible. Coronal NMRI was impossible because of the clinical status of the patient.

A repeated lumbar puncture before myelography this time revealed a blocked Queckenstedt, a glucose content of $87 \mathrm{mg} \%$, protein level of $660 \mathrm{mg} \%$, white blood cells $3 \cdot 410 / \mathrm{mm}^{3}$ with $96 \%$ PMN and red blood cells of $100 / \mathrm{mm}^{3}$. Examination of the CSF showed a few gram positive coccs.

On myelography an extradural block was seen at $T_{1}$ level with contrast collection in the right paravertebral space, suggesting a communication between an abscess and the subarachnoid space (Fig. 3). A supplementary CAT-scan after the myelography showed the amipaque collection to be epidural, and widely spread out in the paravertebral spaces (Fig. 4).

About the same time the results of repeated cultures of CSF and blood appeared, showing a growth of staphylococcus aureus.

A laminectomy was immediately performed from $\mathrm{C} 7$ to $\mathrm{T} 3$ revealing a large abscess in the right paravertebral region of the spine with a fistula into the subarachnoid space. Flucoxacillin was started $4 \times 2 \mathrm{gr}$. IV $/ \mathrm{d}$. The patient made a good postoperative recovery but unfortunately there was no improvement in his neurological state. An incomplete tetraplegia, motor level at C8T1, and sensory level at T10 persisted. A full rehabilitation scheme was started. Wheelchair training was complicated by bilateral hip paraosteoarthropathy. Bladder function control was obtained by intermittent self catheterisation.

\section{Discussion}

Spinal epidural abscess is a rare disease: about one case a year is seen in large referral hospitals (Baker et al., 1975, Ditullio, 1977, Russel et al., 1979, Verner 


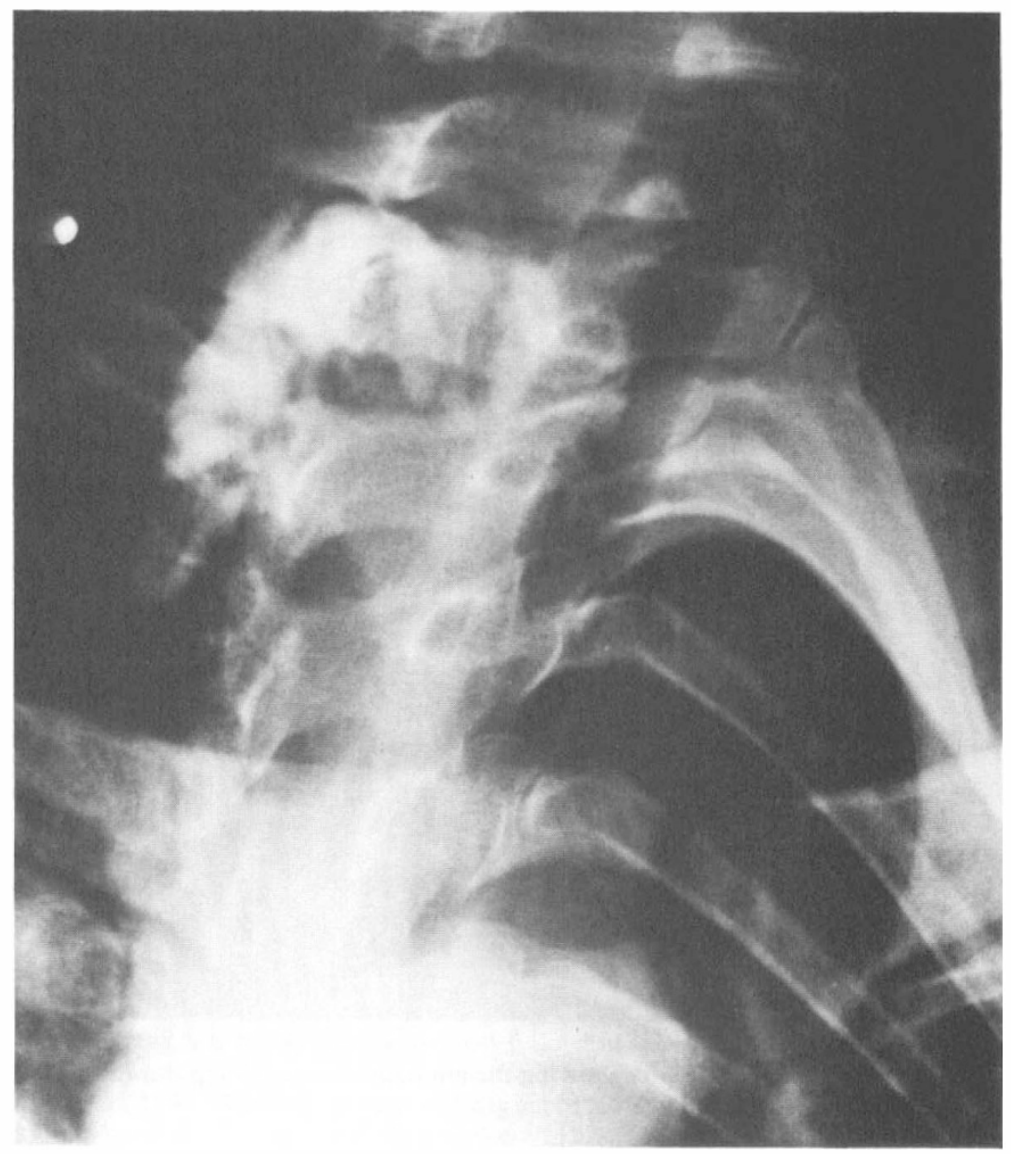

Figure 3. Myelography: contrast collection in the right paravertebral space (T1-T3).

et al., 1985). An incidence of 1 to $9^{\circ}{ }_{0}$ are reported in the total number of nontraumatic paraplegic patients.

Symptoms of fever, backache and limb weakness can be confused with more common diseases, leading to a late diagnosis in a number of patients. Nevertheless early diagnosis is of great importance since laminectomy and drainage of the abscess within 24 to 48 hours after appearance of neurological abnormalities can reverse these (Baker, 1975).

In most patients staphylococcus aureus has been the causative organism, although a wide spectrum of other organisms have been reported (Kaufman et al., 1980). In about a quarter of the cases myobacterium tuberculosis was responsible with a more slowly progression of the disease and without systemic symptoms.

The epidural space is infected either by direct extension from a local process (e.g. vertebral osteomyelitis, decubitus ulcers, abscess elsewhere), or by hematogenously spreading from a distant focus. It is also seen as a complication of epidural catheter placement for anesthesia (Lvowie et al., 1978, Rustin et al., 1983) and after spinal surgery (Ditullio, 1977). In our case a paravertebral 


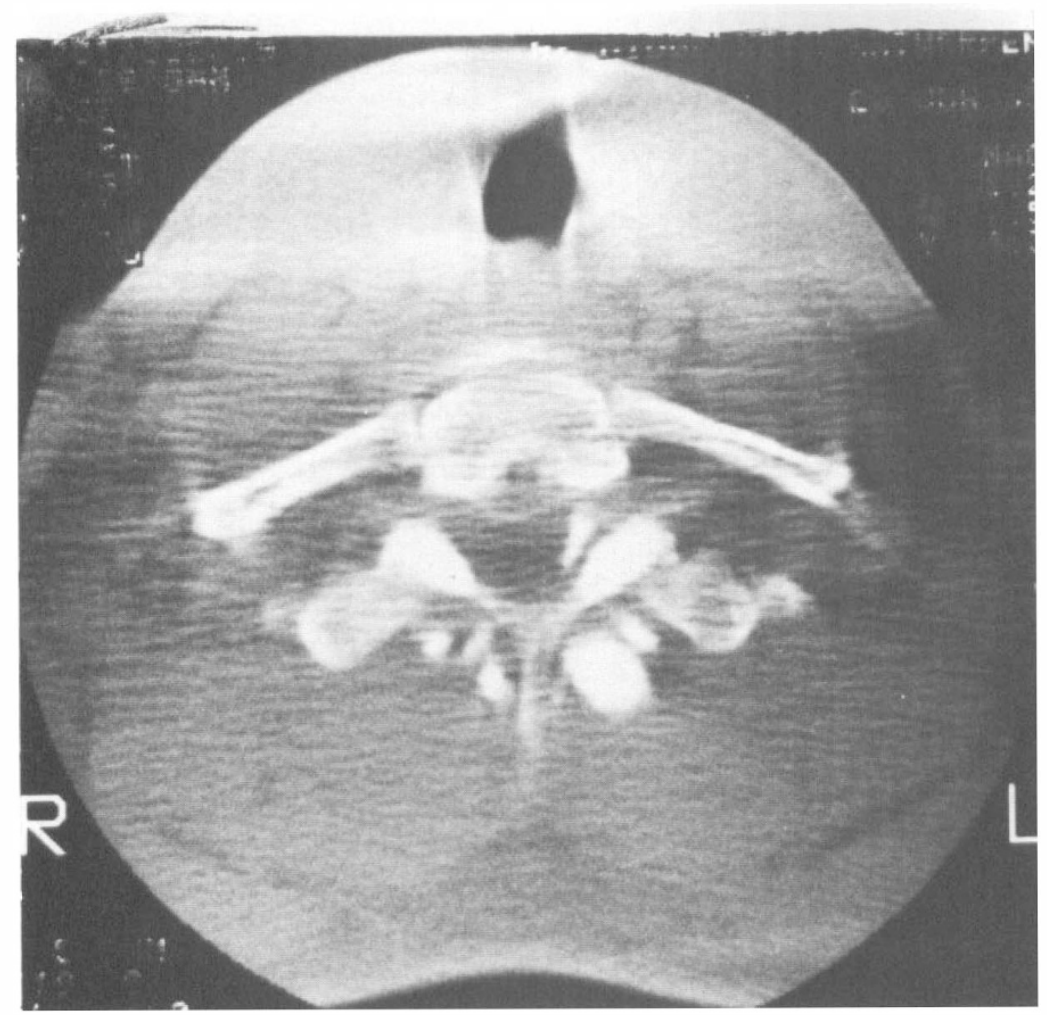

Figure 4. CAT-scan after myelography showing the amipaque collection epidurally and widely spread out in the paravertebral area.

abscess was the cause. The origin of the abscess however is not clear since no skin abnormalities or other foci of infection were found.

Examination of the CSF usually shows an elevated protein content, with levels higher than $100 \mathrm{mg} \%$ and with an almost normal glucose content. The number of white blood cells usually does not exceed 150 cells per $\mathrm{mm}^{3}$ unless pus is encountered as a result of penetration of the abscess. In our case a high white blood cell count was seen from the start suggesting an early penetration of the abscess in the subarachnoid space.

Queckenstedt's test is nearly always positive (Baker et al., 1975, Russell et al., 1979, Verner et al., 1985), but exceptions may occur (Schlossberg P. et al., 1977) as in our case. Only at the second tap a spinal block was found.

The role of CAT-scan and NMRI is not yet determined. Theoretically they offer the advantage of being non-invasive and less dangerous, and of giving more information as bone and other near structures are visualised (Har et al., 1983, Norman et al., 1983).

In our patient a CAT-scan showed a slight swelling of the perivertebral area, suggestive of inflammatory pathology. However a definite abscess or medulla alterations were not seen. Similar findings were reported by König et al., 1985, who reported a marked swelling of the paravertebral region in a case of 
a paravertebral abscess after contamination with a peridural catheter. The NMRI detected an abnormality of the medulla and subarachnoid space without a definite diagnosis. No abscess was seen. To our knowledge this is the first report of NMRI findings of an epidural abscess. Both CAT-scan and NMRI were rather disappointing in contrast to myelography. In our experience myelography remains the examination of choice, but further experience is necessary to be certain.

\section{References}

Altrocchi PH 1973 Acute spinal epidural abscess vs. acute transverse myelopathy. Archives of Neurology (Chic.) 9:17.

BAKER AS, OJEMANN RG, SwARTz MN, et al. 1975 Spinal epidural abscess. New England Journal of Medicine 293:463-468.

BRown KDE 1979 Non traumatic paraplegia in Subsaharan Africa. East African Medical Journal 56:300.

Ditullio MV 1977 Intramedullary spinal abscess: a case report with a review of 53 previously described cases. Surgical Neurology 7:351-354.

Hakin RN, Burt AA, Cook JB 1979 Acute spinal abscess. Paraplegia, pp. 330-336.

HANCOCK DO 1973 A study of 49 patients with acute spinal extradural abscess. Paraplegia 10:285.

HAR JS, et al. 1983 NMR Imaging of the spine. American Journal of Roentgenology 141(6):1137-45.

IwEGBU CG, 1983 Paraplegia secondary to pyogenic epidural abscess. East African Medical Journal 60:640-644.

KaUfman DM, Kaplan JG, Litman N 1980 Infectious agents in spinal epidural abscess. Neurology 844-849.

KÖNIG HJ, SCHLEEP J, KRÄHLING KH 1985 Ein fall von Querschnittsyndrom nach Kontamination eines Periduralkatheters. Regional Anaesthesie 8:60-62.

Lvowie DJ, FARILEY HB 1978 Epidural abscess following spinal anesthesia. Anesthesia and Analgesia 57:351-352.

Norman D, et al. 1983 Magnetic resonance imaging of the spinal cord and causal potentials and limitations. American Journal of Roentgenology 141(6):1147-52.

Patronas NJ, Marx WJ, Duda EE 1979 Radiographic presentation of spinal abscess in the subdural space. American Journal of Roentgenology 132:138-139.

Russell NA, Vaughan R, MoRley TP 1979 Spinal epidural infection. Canadian Journal of Neurological Sciences 6:325-328.

Rustin MH, FLYNN MD, CoOMES EN 1983 Acute sacral epidural abscess following local anesthetic injection. Postgraduate Medical Journal 59:399-400.

Schlossberg D, Shulman JA 1977 Spinal epidural abscess. Southern Medical Journal 70:669-673.

Verner EF, Musher DM 1985 Spinal epidural abscess. Clin. North America. 379-384.

YANG S 1982 Spinal epidural abscess. New Zealand Medical Journal. 302-304. 